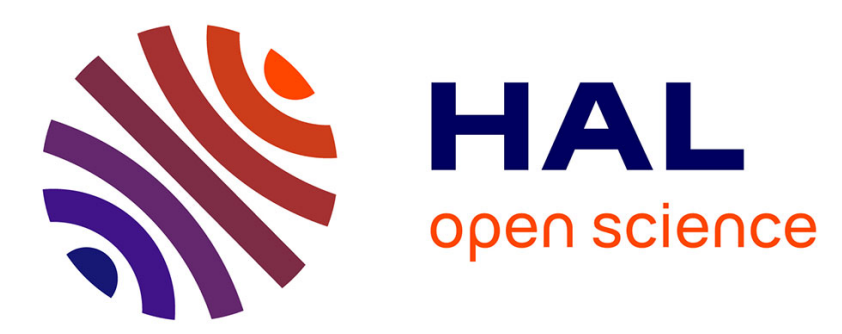

\title{
Design and preliminary tests of a twin coil HTS SMES for pulse power operation
}

\author{
Arnaud Badel, Pascal Tixador, Kévin Berger, Marc Deleglise
}

\section{To cite this version:}

Arnaud Badel, Pascal Tixador, Kévin Berger, Marc Deleglise. Design and preliminary tests of a twin coil HTS SMES for pulse power operation. Superconductor Science and Technology, 2011, 24 (5), pp.055010. 10.1088/0953-2048/24/5/055010 . hal-00574565

\section{HAL Id: hal-00574565 \\ https://hal.science/hal-00574565}

Submitted on 8 Mar 2011

HAL is a multi-disciplinary open access archive for the deposit and dissemination of scientific research documents, whether they are published or not. The documents may come from teaching and research institutions in France or abroad, or from public or private research centers.
L'archive ouverte pluridisciplinaire HAL, est destinée au dépôt et à la diffusion de documents scientifiques de niveau recherche, publiés ou non, émanant des établissements d'enseignement et de recherche français ou étrangers, des laboratoires publics ou privés. 


\title{
Design and preliminary tests of a twin coil HTS SMES for pulse power operation
}

\author{
Arnaud Badel $^{1,2}$, Pascal Tixador ${ }^{1,2}$, Kevin Berger ${ }^{3}$ \\ and Marc Deleglise ${ }^{1}$ \\ ${ }^{1}$ Neel Institute-CNRS, 25 rue des Martyrs, 38042 Grenoble, France \\ ${ }^{2}$ G2ELab-Grenoble INP/UJF-CNRS, ENSE3, 961, rue Houille Blanche 38402 St Martin \\ d'Hères, France \\ ${ }^{3}$ GREEN-Université Henri Poincaré, Faculté des Sciences et Technologies, \\ 54506 Vandoeuvre lès Nancy, France \\ E-mail: arnaud.badel@grenoble.cnrs.fr
}

Received 20 October 2010, in final form 6 February 2011

Published 7 March 2011

Online at stacks.iop.org/SUST/24/055010

\begin{abstract}
The design of a twin coil $2 \times 200 \mathrm{~kJ}-1 \mathrm{MW}$ pulse power high temperature superconductor (HTS) superconducting magnetic energy storage (SMES) demonstrator is presented. Its aim is to test at small scale various possibilities of electromagnetic launcher powering. The foreseen operation modes include high voltage discharge in power capacitors, sequential discharges of identical energies from two coupled coils, and XRAM current multiplication. Special attention was paid to the arrangement of the coils for the energies discharged to be equal. The coils are cooled by conduction from three cryocoolers; the thermal design was optimized in order to maintain the coils around $15 \mathrm{~K}$ in spite of the high number of current leads required for XRAM operation (eight). Preliminary tests of the demonstrator are also presented, showing that the thermal and electrical characteristics are in very good agreement with the design objectives.
\end{abstract}

(Some figures in this article are in colour only in the electronic version)

\section{Introduction}

A SMES (superconducting magnetic energy storage) stores energy in the magnetic flux density created by a short-circuited superconducting magnet [1]. It is, along with the capacitor, the only way to store energy directly available as electricity without conversion. It shares with the capacitor a rather low energy density, limited according to the virial theorem [2] by the maximum tensile stress on the conductor. On the contrary, the maximal power is not limited, at least theoretically. An SMES is fundamentally a current source, its voltage being fixed by the load. For pulse power operations, the voltage may reach high values (several $\mathrm{kV}$ ); it is then necessary to ensure a good electrical insulation of the coil and its current leads. The area of application of a pulse power SMES extends over all areas where a high power current source is needed, from manufacturing applications such as magnetoforming to military or aerospace applications such as railguns, catapults or payload electromagnetic launchers [3, 4]. The interest of a high temperature superconductor (HTS) for an SMES is that it offers larger current densities under high magnetic flux densities than a low temperature superconductor (LTS), and has greater thermal stability due to the higher temperature margin. Several devices operating around $4.2 \mathrm{~K}$ were successfully realized and tested in recent years, especially using BSCCO conductors [5-7]. With HTSs, operation over $15 \mathrm{~K}$ is also possible. This leads to considerable savings in terms of cooling cost and facilitates the use of conductioncooling, as it makes the temperature drops caused by electrical insulation interfaces more easy to accept. Moreover, additional gains in stability are obtained due to the specific heat increase [8]. For example, the specific heat of silver, which represents around $60 \%$ of the total amount of material in a BSCCO tape, is multiplied by 100 between 4.2 and $15 \mathrm{~K}$. This is particularly interesting for pulse power devices, which are subjected to losses caused by fast discharge. Some large scale conduction-cooled devices operating around $20 \mathrm{~K}$ were developed and tested in recent years, most of them using BSCCO [9]. The use of $\mathrm{YBCO}$, which is very promising in terms of both performance and cost, is still limited by the difficulty in obtaining long lengths and connecting them together. The present day high cost is another issue. 


\section{Pancake copper plate connection}

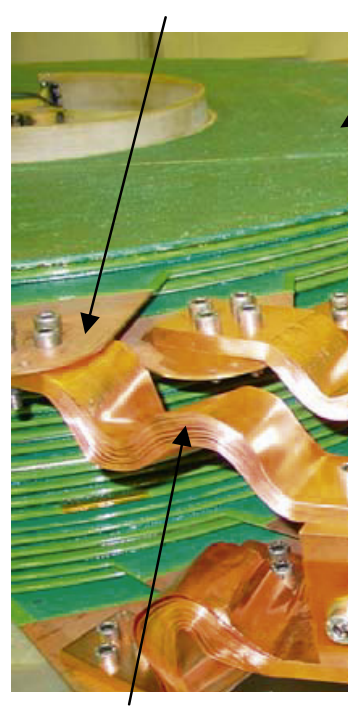

Flexible copper element
Pancake winding

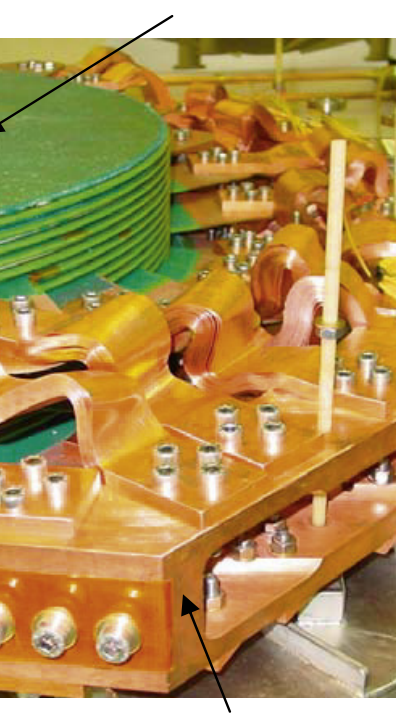

Croissant-shaped copper cold plate

Figure 1. SMES I pancake stack and cooling plates.

In the framework of a DGA (Délégation Générale de l'Armement), the HTS SMES demonstrator 'SMES I' was constructed and tested in 2007 [10]. It was a $15 \mathrm{H}$ solenoid conduction-cooled at $20 \mathrm{~K}$ by GM (Gifford MacMahon) cryocoolers. The coil was made of 26 pancakes, wound with Nexans conductors made of three or four BSCCO PIT tapes soldered together and reinforced in some locations with a stainless steel tape. The pancakes were wound on insulated copper plates that served as mechanical holding as well as thermal drain, bringing the cooling power to the winding (figure 1). It quenched at $250 \mathrm{~A}$ during the tests, storing about $450 \mathrm{~kJ}$. It demonstrated the feasibility of large conductioncooled HTS SMES, and especially the efficiency of the cooling system design that was developed.

The purpose of the new demonstrator (SMES II) is to test at small scale various discharge configurations for electromagnetic launcher (EML) powering. It is an upgrade of SMES I, developed following the same design principles and re-using the 26 pancakes from SMES I plus two additional ones wound similarly.

Usually, EMLs are powered with high power capacitor banks. One objective of SMES II is to test the possibility of rapidly reloading these discharge capacitors with an SMES. In order to transfer a substantial energy to the capacitors, a high operating voltage is required. When compared to the first version, the electrical insulation of both the pancakes and the current leads is improved to withstand up to $4 \mathrm{kV}$. With this increased operating voltage, a maximum pulse power of $1 \mathrm{MW}$ can be reached.

SMES II must also be capable of discharging sequentially the same energy $(200 \mathrm{~kJ})$ from two coupled coils, in order to test the possibilities of powering segmented launchers. The 28 pancakes are thus to be arranged in two groups, forming

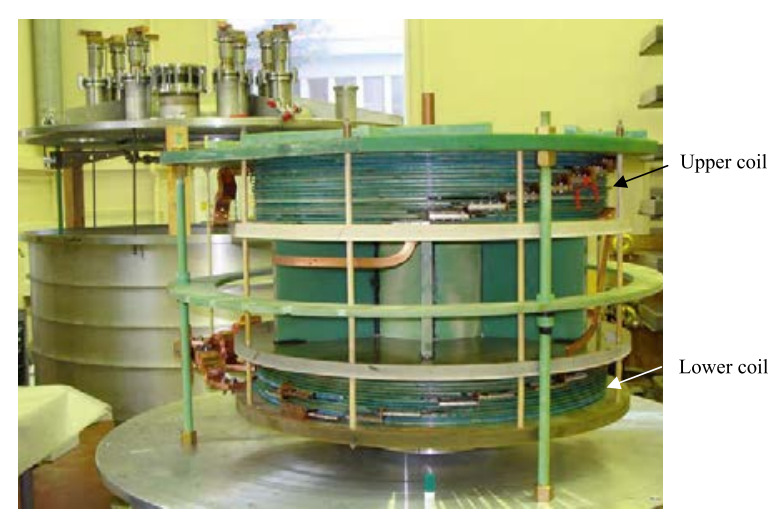

Figure 2. SMES II pancake arrangement forming two coupled coils.

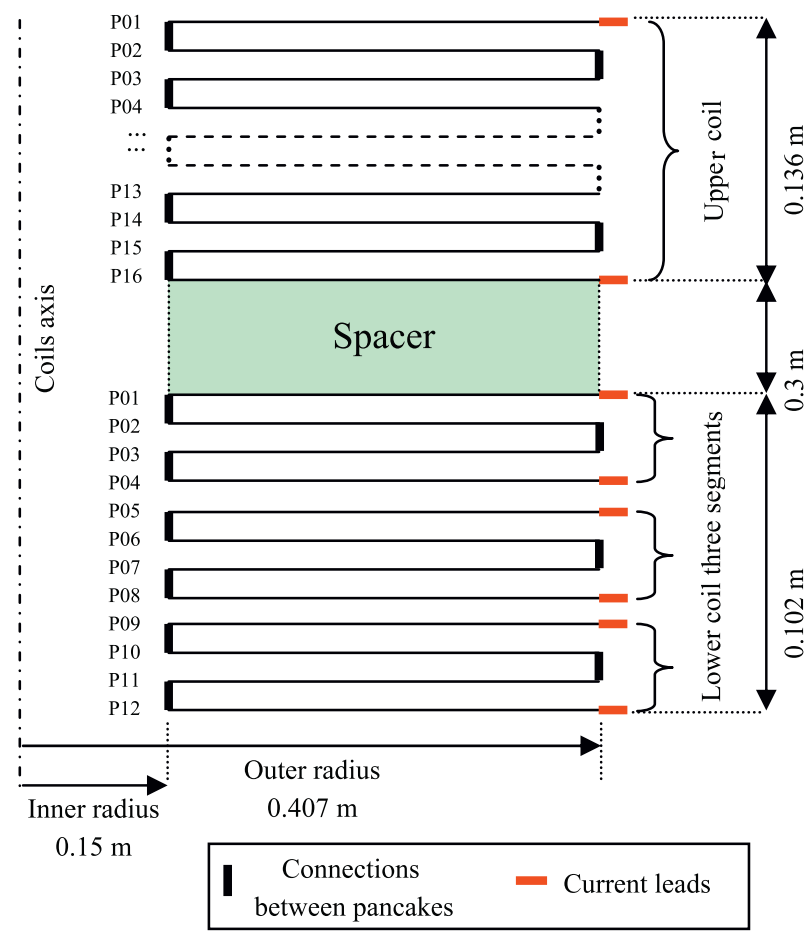

Figure 3. SMES II layout.

the two independent coils. These two windings are one on top of the other in the same cryostat (figure 2). Both the number of pancakes forming each coil and the distance between them were optimized for this purpose. This will be discussed in section 2 .

EML requires very high current, from several hundreds of kA to several MA [11]. Direct powering of EML with HTS SMES is very challenging. The XRAM principle, dual of the MARX concept commonly used to obtain high voltages with a set of capacitors, could be used to obtain the required current [12]. It consists in charging several coils in series and discharging them in parallel to sum up their elementary currents. In order to test this concept, the lower coil of SMES II is made of three independent elements, each of them having current leads in order to be connected outside the cryostat. With this setting, an output current of $750 \mathrm{~A}$ can be obtained. 
Table 1. Energies stored in the coils before and after the first coil discharge.

\begin{tabular}{llll}
\hline & Energy in L1 & Energy in M1-2 & Energy in L2 \\
\hline Before $\mathrm{L}_{1}$ discharge & $E_{1 \text { init }}=1 / 2 L_{1} I_{1}^{2}$ & $E_{\text {mut init }}=M_{1-2} I_{1} I_{2}$ & $E_{2 \text { init }}=1 / 2 L_{2} I_{2}^{2}$ \\
& & $M_{1-2}=k \sqrt{L_{1} L_{2}}$ & \\
After $\mathrm{L}_{1}$ discharge & $E_{1 \text { discharged }}=E_{1 \text { init }}\left(1-k^{2}\right)$ & $E_{\text {mut stored }}=0$ & $E_{2 \text { stored }}=E_{2 \text { init }}+E_{\text {mut init }}+E_{1 \text { init }} k^{2}$ \\
& $E_{1 \text { stored }}=0$ & & Current overcharge $: \Delta I_{2}=k \sqrt{L_{1} / L_{2}} I_{1}^{2}$ \\
\hline
\end{tabular}

Table 2. Simulation results for $200 \mathrm{~kJ}$ sequential discharges.

\begin{tabular}{|c|c|c|c|c|c|c|c|c|c|c|c|c|c|c|}
\hline $\begin{array}{l}\text { Pancake number in } \\
\text { upper/lower coil }\end{array}$ & 26 & 2 & 24 & 4 & 22 & 6 & 20 & 8 & 18 & 10 & 16 & 12 & 14 & 14 \\
\hline Inductance $(\mathrm{H})$ & 16.0 & 0.14 & 14.0 & 0.53 & 12.1 & 1.16 & 10.3 & 2.00 & 8.57 & 3.00 & 6.6 & 4.3 & 5.51 & 5.51 \\
\hline Distance $(\mathrm{mm})$ & \multicolumn{2}{|c|}{1} & \multicolumn{2}{|c|}{24} & \multicolumn{2}{|c|}{55} & \multicolumn{2}{|c|}{103} & \multicolumn{2}{|c|}{176} & \multicolumn{2}{|c|}{313} & \multicolumn{2}{|c|}{1000} \\
\hline Coupling coefficient (\%) & \multicolumn{2}{|c|}{64} & \multicolumn{2}{|c|}{55} & \multicolumn{2}{|c|}{46} & \multicolumn{2}{|c|}{37} & \multicolumn{2}{|c|}{26} & \multicolumn{2}{|c|}{14} & \multicolumn{2}{|c|}{2} \\
\hline $\begin{array}{l}\text { Initial current in } \\
\text { upper/lower coil (A) }\end{array}$ & 207 & 264 & 203 & 292 & 205 & 279 & 212 & 272 & 223 & 269 & 250 & 261 & 269 & 264 \\
\hline $\begin{array}{l}\text { Lower coil current after } \\
\text { upper coil discharge (A) }\end{array}$ & \multicolumn{2}{|c|}{1695} & \multicolumn{2}{|c|}{865} & \multicolumn{2}{|c|}{588} & \multicolumn{2}{|c|}{449} & \multicolumn{2}{|c|}{365} & \multicolumn{2}{|c|}{305} & \multicolumn{2}{|c|}{269} \\
\hline
\end{tabular}

\section{Magnetic design}

In order to discharge sequentially the same energy from two short-circuited coils, the energy exchange induced by their coupling during the first discharge must be considered. The two coil inductances, their respective operating currents and the magnetic coupling coefficient between them are the parameters with which the energy available during the two discharges may be adjusted, following the energy storage equations summarized in table 1.

With our already existing set of 28 pancakes assembled two by two, the possibilities for the two coil inductances are limited. We simulated the seven possible combinations using the finite element software Flux ${ }^{\circledR}$, varying the distance and the operating currents to obtain $200 \mathrm{~kJ}$ discharges successively from the upper and the lower coils (table 2). The conductor must remain superconducting and dissipate less than the available cooling power for the coil temperatures not to drift. In consequence, the constraint on our design is to have the operating current below $80 \%$ of the critical current during the four phases of operation (charge of the two coils, energy storage, discharge of the first coil and overcharge of the second, discharge of the second coil). The first five solutions are thus impossible, due to the excessive over current in the lower coil after the upper coil discharge. The last solution (with identical inductances) can be satisfied with regards to the operating currents but requires almost no coupling between the coils and thus a large distance between them $(1 \mathrm{~m})$. This is an issue for the realization of the cryostat, and would lead to a very low energy per volume. Finally, the best solution is the sixth one, an 8-6 double pancake arrangement respectively charged at 250 and $261 \mathrm{~A}$, with $0.31 \mathrm{~m}$ between the two windings. After the upper coil discharge, the lower coil current reaches $305 \mathrm{~A}$, which in this configuration is still below $80 \%$ of $I_{\mathrm{c}}$, as the magnetic flux density is lower after the upper coil discharge. The simulated magnetic flux density, before and after the discharge of the upper coil, is presented in figure 4.

\section{Thermal design}

For SMES I, two AL 330 cryocoolers by Cryomech [13] were used. The first one was used to cool the magnet; the cooling power was distributed to the winding by flexible copper plates connected to the pancakes' copper backing. The current leads were made of two parts: a resistive segment, from the outside of the cryostat down to an intermediary thermalization, and a superconducting segment from this thermalization down to the coil. The second cryocooler was used to maintain the temperature of this thermalization around $30 \mathrm{~K}$, for the lower segment to remain superconducting, and was also cooling the active thermal shield. With this setting the losses on the coil with currents much lower than 300 A were very low (1-2 W) and the operating temperature was around $15 \mathrm{~K}$.

For SMES II the same architecture is used. The issue is that with a limited cooling power ( 3 AL 330 cryocoolers), two coils and eight current leads must be cooled (two leads for the upper coil and $2 \times 3$ for the lower coil due to XRAM operation). As the coils are separated by $0.3 \mathrm{~m}$, each of them requires a dedicated cryocooler, so there is only one cryocooler available for the cooling of all the current leads. Moreover, as the SMES I cryostat flanges are re-used for SMES II, the room available around the coils to fit the thermalization interfaces is limited. The new current lead system is designed considering these constraints, with the objective of limiting the losses on each coil to around $2 \mathrm{~W}$ for the temperatures to stay around $15 \mathrm{~K}$, taking into account the resistive losses of the coils operating at the rated current close to the critical one.

\subsection{High $T_{c}$ superconducting current leads}

For the superconducting part of the current leads, two different cases are studied: the upper coil is classical, thus having only two leads, but the distance between this coil and the top of the cryostat is short. We re-use the Nexans ${ }^{\circledR}$ bulk BSCCO leads previously used in SMES I [14]. Their low thermal conductivity ensures a good thermal isolation in spite of their 

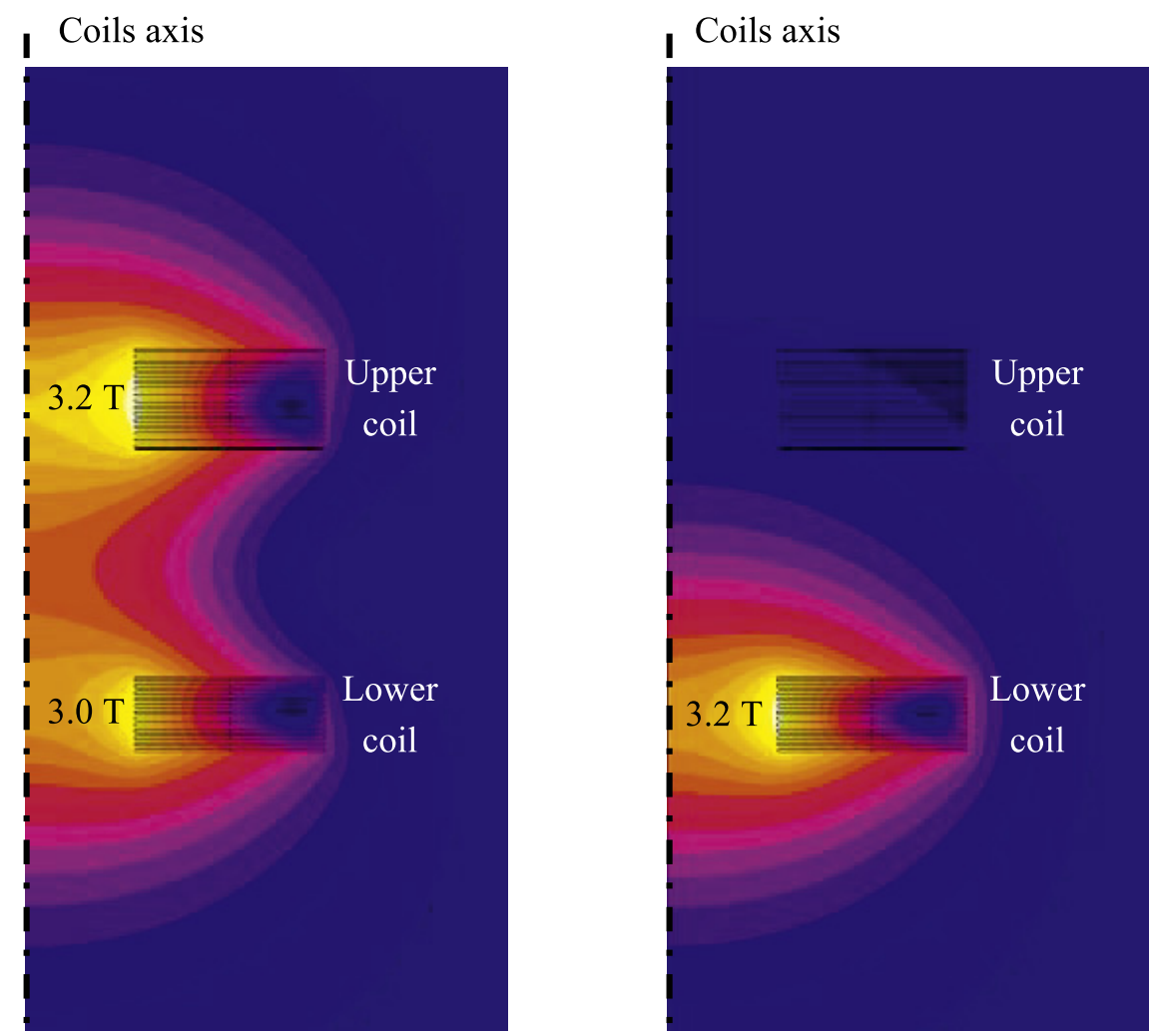

Figure 4. Magnetic flux density before (left) and after (right) the upper coil discharge.

short length $(0.2 \mathrm{~m})$, limiting the losses on the upper coil to about $40 \mathrm{~mW}$ when the lead's upper end is thermalized at $50 \mathrm{~K}$.

The lower coil consists of three stacked coil elements, having six leads with different lengths from 0.57 to $0.66 \mathrm{~m}$. We decided to build our own leads because of the implementation specificities in our system, with not much room available to insert them. Bulk superconductor was not suitable in this case because it is brittle and potentially vulnerable to thermal expansion effects over long lengths. We used AMSC ${ }^{\circledR}$ PIT BSCCO tapes with a gold/silver alloy matrix. This kind of tape is specifically designed for current leads; it has a much lower thermal conductivity when compared to pure silver matrix tapes. Five tapes are used in parallel for each lead, to ensure operation at $50 \mathrm{~K}$ under up to $0.4 \mathrm{~T}$ (\|flux density) and $300 \mathrm{~A}$ with almost no dissipation. The conduction losses on the lower coil due to these leads are about $240 \mathrm{~mW}$. The tapes are housed in a grooved fiber glass rod, and soldered together at each extremity with custom-made copper connectors (figure 5). A process was developed to ensure reliable soldering without damaging the tapes.

\subsection{Resistive current leads and thermalizations}

For the upper parts of the current leads, resistive conductor is used. Conduction-cooled thermalizations maintain the cold ends of these leads at an acceptable temperature $(50 \mathrm{~K})$ for the superconducting leads that come below.

3.2.1. Thermalization interface materials. Conductioncooled thermalization is an issue for fast discharge devices

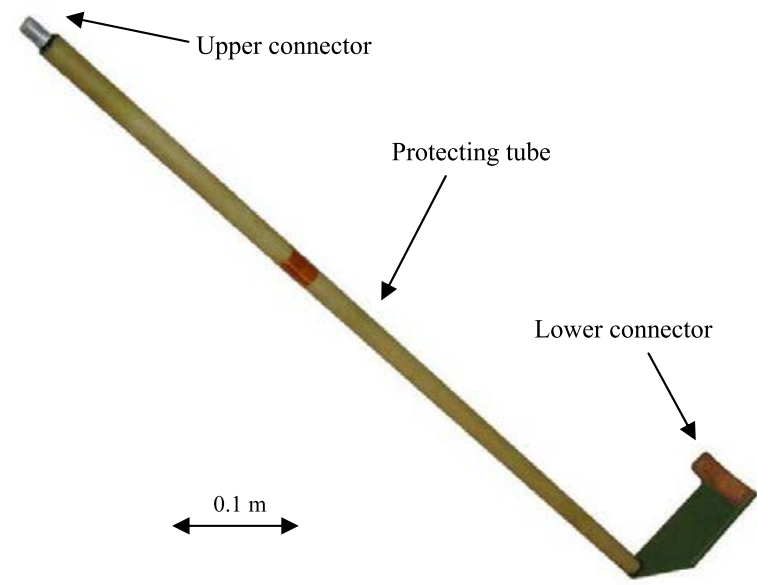

Figure 5. Superconducting current lead segment with connectors.

as the interface must have the highest thermal conductivity possible while isolating from high voltage $[15,16]$. Moreover, thermalization interfaces withstand considerable stresses due to the differences of thermal expansion between the materials in contact. In the first version of our system, the interface was composed of two layers. The current leads' contact surfaces were coated with epoxy, forming a thin layer of about $0.2 \mathrm{~mm}$. Redux $^{\circledR}$ film (an epoxy film with low curing temperature) was used to glue the surfaces together with the cold plates [14]. Mechanically and electrically this interface was satisfying but its surface thermal conductivity was quite low, $200 \mathrm{~W} \mathrm{~K}^{-1} \mathrm{~m}^{-2}$ around the operating temperature $(20 \mathrm{~K})$. For the new version, 


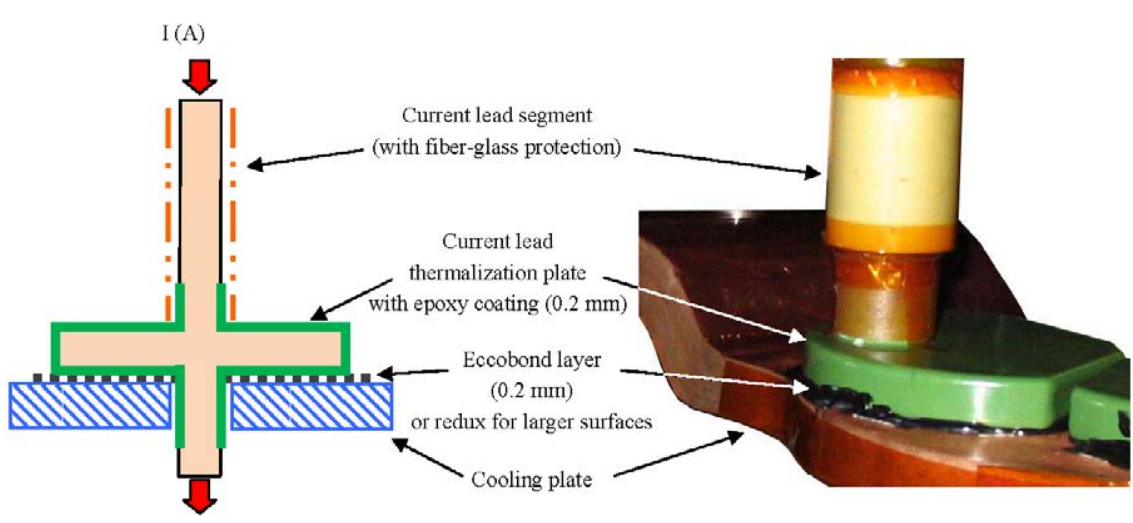

Figure 6. Thermalization interfaces: schematic view (left) and practical implementation (right).

we conducted experiments with other interfaces, in order to reduce the temperature drops on these interfaces and thus to optimize the use of the available cooling power.

By replacing the $\operatorname{Redux}^{\circledR}$ film with a thin layer $(0.2 \mathrm{~mm})$ of Eccobond $^{\circledR}$, the surface thermal conductivity of the interface reaches $450 \mathrm{~W} \mathrm{~K}^{-1} \mathrm{~m}^{-2}$ at around $20 \mathrm{~K}$. In consequence, the temperature drop at the insulation interface is divided by 2 . The electrical insulation remains satisfying, with a breakdown voltage reproducibly higher than $5 \mathrm{kV}$, but it appeared during tests that it is mechanically weak on large surfaces. We therefore used this new interface only for the small thermalization surfaces (figure 6), and continued to use interfaces made with Redux for the larger ones.

3.2.2. Resistive lead optimization principle. The optimization of the resistive part of the current leads is based on the classical equations stating that the current lead losses are minimal if the thermal flux on the hot end is null under the current considered for the design, meaning that the heat generated by the Joule effect exactly compensates the conduction losses:

$$
\begin{gathered}
Q_{0}^{*}=I \times \sqrt{2 \int_{T_{0}}^{T_{1}} \lambda(q) \rho(q) \mathrm{d} q} \\
{\frac{L^{*}}{S} I}^{*}=\int_{T_{0}}^{T_{1}} \frac{\lambda(T)}{\sqrt{2 \int_{T_{0}}^{T} \lambda(q) \rho(q) \mathrm{d} q}} \mathrm{~d} T
\end{gathered}
$$

with $\lambda$ the thermal conductivity and $\rho$ the electrical resistivity of the current lead material, $T_{0}$ the temperature of the cold end and $T_{1}$ on the hot end, $Q_{0}$ the optimized thermal flux on the cold end, $I$ the designed current and $L / S$ the optimized form factor of the current lead (length over area ratio) for the current $I$.

In order to calculate precisely the behavior of the complete current lead system, all the thermalization elements (cold plates, isolation interfaces, etc) must be considered in addition to the current lead segments. A numerical simulation tool was developed for this task using Matlab ${ }^{\circledR}$. It is fed with the values of the different electrical interfaces measured experimentally, the equivalent conductivities of the different cold plates

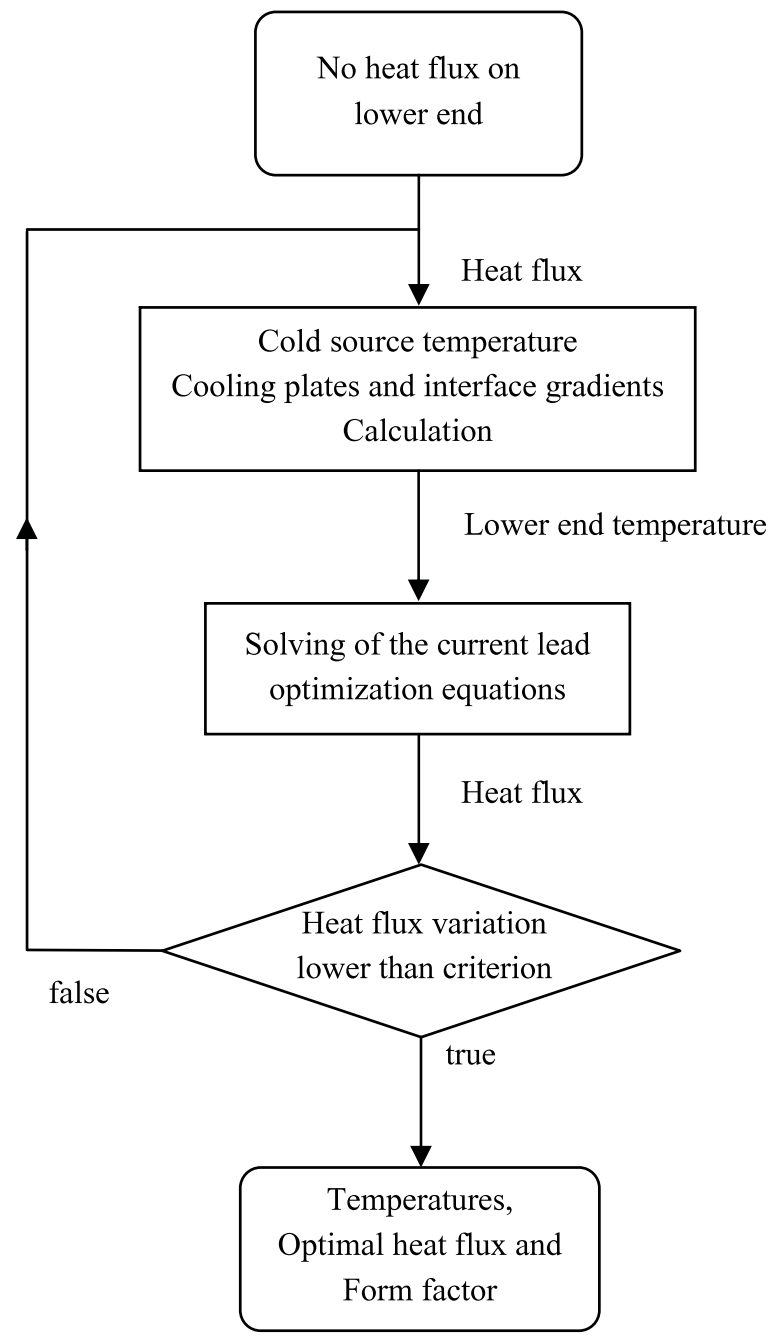

Figure 7. Solving principle of the resistive current lead simulation tool.

calculated by the finite element method (using Flux $3 \mathrm{D}^{\circledR}$ ) and the cooling power against temperature characteristic of the cold sources. Its solving principle is presented in figure 7 .

From temperature on the upper end and the operating current, the code calculates the temperature and heat flux on the lower end using an iterative method. In the first step the 


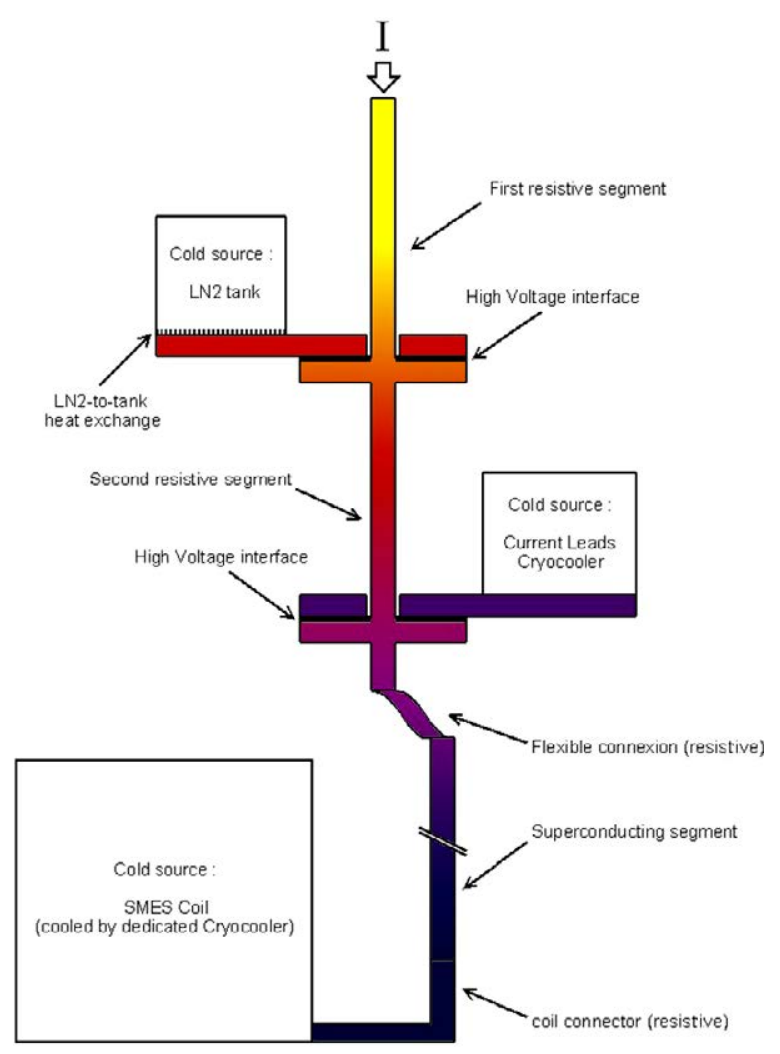

Figure 8. Schematic view of a current lead.

lower end temperature is calculated as if there was no heat flux, meaning that the thermalizations and cold source are supposed perfect. For example, if the cold source is a cryocooler, the initial temperature chosen is its no-load temperature. If the cold source is a liquid nitrogen tank, it will be considered at $77 \mathrm{~K}$. The optimization equations are then solved, and the obtained heat flux is used to calculate the actual temperature of the cold source, taking into account its response to the heat load. The temperature drops in the various cold plate and thermalization interfaces are also calculated with this heat flux value. In the next step the new value for the lower end temperature is calculated, and used to re-calculate the optimized heat flux. The process is repeated until the variation of the obtained heat flux between two steps is lower than a given criterion. The convergence is very fast, less than ten iterations are usually enough to reach a $0.05 \mathrm{~W}$ criterion.

3.2.3. SMES II resistive current lead design. A simple calculation based on the generally admitted level of $40 \mathrm{~W} \mathrm{kA}^{-1}$ for conduction-cooled current leads gives a minimal cooling power of around $96 \mathrm{~W}$ for the eight leads of SMES II, which leads to a cold head temperature of about $38 \mathrm{~K}$ for our cryocooler. Considering the temperature drops in the current lead thermalization interfaces, it seems difficult to guarantee an operation temperature below or around $50 \mathrm{~K}$ for the current leads using this cryocooler alone, even using the new interfaces to reduce the temperature drops. This was confirmed by the first results obtained using the simulation tool presented above, taking into account the restrictions imposed on the design in
Table 3. Resistive current lead design results.

\begin{tabular}{|c|c|c|}
\hline Resistive current lead & Upper segment & Lower segment \\
\hline Cooling source & Liquid nitrogen & Cryocooler \\
\hline Material & Brass & Brass \\
\hline $\begin{array}{l}\text { Upper end } \\
\text { temperature }(\mathrm{K})\end{array}$ & 300 & 108 \\
\hline $\begin{array}{l}\text { Lower end } \\
\text { temperature }(\mathrm{K})\end{array}$ & 108 & 47 \\
\hline Aspect ratio $(L / S)$ & 2466 & 1092 \\
\hline $\begin{array}{l}\text { Heat flux under operation } \\
\text { (for each lead) (W) }\end{array}$ & 18 & 7.5 \\
\hline $\begin{array}{l}\text { Heat flux without } \\
\text { current (W) }\end{array}$ & 8 & 2.8 \\
\hline $\begin{array}{l}\text { Temperature drop in } \\
\text { isolation layer }(\mathrm{K})\end{array}$ & 10 & 9 \\
\hline $\begin{array}{l}\text { Temperature drop in } \\
\text { cooling plates }(\mathrm{K})\end{array}$ & 2 & 2 \\
\hline $\begin{array}{l}\text { Temperature of the } \\
\text { cooling source }(\mathrm{K})\end{array}$ & $\begin{array}{l}80 \text { (LN2 tank } \\
\text { cold plate) }\end{array}$ & $\approx 30$ \\
\hline
\end{tabular}

terms of available space in the cryostat. We therefore studied the possibility of implementing a two-stage thermalization, with an additional cold source.

As the optimum for a simple current lead having one thermalization is to have no heat flux on the hot end, the optimum for a current lead having two thermalizations is obtained by considering a different current lead segment for each thermalization, and optimizing them one after the other. The simulation tool we developed may be used following this idea: the first segment calculated is the hottest one, whose temperature on the upper end is known (room temperature). This first optimization gives us the temperature of the second segment upper end which is then calculated.

Finally, the SMES II current lead design features a first thermalization cooled by conduction from a liquid nitrogen tank fitted in the upper dished head of the cryostat, and a second thermalization cooled by the cryocooler (figure 8 ). The simulation results for this design are summarized in table 3; it guarantees an operation temperature below $50 \mathrm{~K}$ for the current leads with a reasonable safety margin of $8 \mathrm{~K}$, the liquid nitrogen tank absorbing up to $144 \mathrm{~W}$ when the device is at its maximal current (300 A, at the end of the upper coil discharge).

\subsection{Coil cooling}

The losses on the coils are of two types: on one hand the thermal losses which are permanent, on the other hand the Joule and dissipation losses that depend on the current. Thermal losses are mainly due to conduction through the current leads, which were evaluated in section 3.1 and radiation. Joule losses are due to the connections between pancakes and the connections between each coil and its current leads (figure 3). They were evaluated through experimental measurements of the different contact resistances. The pancake connection resistances were measured at around $0.3 \mu \Omega$ whereas the current lead connections were measured at $1.3 \mu \Omega$. The resulting losses on the upper and lower coils are respectively $0.34 \mathrm{~W}$ and $0.96 \mathrm{~W}$.

Finally dissipation losses are distributed on the windings and only appear when the current reaches values close to the 
Table 4. Heat load on each cryocooler and resulting temperature.

\begin{tabular}{lccc}
\hline Cryocooler & Upper coil & Lower coil & $\begin{array}{l}\text { Current leads and } \\
\text { thermal shield }\end{array}$ \\
\hline $\begin{array}{l}\text { Thermal losses }(\mathrm{W}): \\
\quad \text { Radiation }\end{array}$ & 0.58 & 0.42 & 10 \\
$\quad \begin{array}{l}\text { Conduction (structure) } \\
\quad \text { Conduction (leads) }\end{array}$ & 0.01 & 0 & 0.2 \\
Total without current (W) & 0.04 & 0.24 & 22.4 \\
$\begin{array}{l}\text { Cryocooler minimal } \\
\text { temperature (K) }\end{array}$ & $\approx 11$ & 0.66 & 32.6 \\
$\begin{array}{l}\text { Heat generation (W): } \\
\quad \text { Resistive connections (or }\end{array}$ & 0.34 & $\approx 11$ & $\approx 22$ \\
$\quad$ resistive conductor) & & 1.08 & 37.6 \\
$\quad$ Conductor dissipation & 7.8 & 5.8 & 0 \\
Total under operation (W) & 8.77 & 7.54 & 70.2 \\
$\begin{array}{l}\text { Cryocooler temp. } \\
\text { under operation (K) }\end{array}$ & $\approx 13$ & $\approx 13$ & $\approx 30$ \\
\hline
\end{tabular}

critical current. They were evaluated under the pessimistic hypothesis that the total length of conductor is operating at the design limit, $0.8 I_{c}$. The transition resistive index (' $n$ ' value) is supposed to be 15 . In this case the losses depend only on their conductor length; they are respectively 7.8 and $5.8 \mathrm{~W}$ for the upper and lower coils. A summary of the total heat load for each coil cryocooler, with no current and under the maximal current is presented in table 4. It shows that the proposed design effectively ensures operation below $15 \mathrm{~K}$ for the two coils, as expected.

\section{Protection}

During the tests of the SMES I prototype, one of the quenches led to localized damage on one of the pancakes. The damage was repaired by removing the few turns concerned, but this event demonstrated the vulnerability of this kind of HTS conduction-cooled winding against small and undetected quench developments, and the lack of sensitivity of our detection bridge in the $10 \mathrm{mV}$ range.

\subsection{Active isolation}

In this matter, the characteristics of the new prototype SMES II-with voltage operation up to $4 \mathrm{kV}$ - change the situation. On one hand, the high voltage operation enhances the safety of operation by enabling a faster discharge for protection purposes. On the other hand, the ratio between the voltage level to be detected and the operating voltage is much lower. To guarantee a sensitive and reliable detection of transition in this context, a novel detection system was designed $[17,18]$. Like the previous one, it features a detection bridge measuring the imbalance between the lower and upper parts of the protected coil, but the bridge itself and the detection electronics are placed behind high voltage fast switches. These switches (reed switches) are controlled by the detection and command system of the SMES; they are opened shortly before the discharge. With this method, the bridge is isolated from the high voltage before it appears. It therefore can be designed without any signal attenuation, improving the detection sensitivity: a factor of 40 was measured.

\subsection{Coupling compensation}

As the SMES II features two coupled coils, there are in fact two detection bridges. The first one, corresponding to the upper coil always being discharged first, is classical. The second one, corresponding to the lower coil being discharged a second time, features an additional bridge compensating the couplinginduced voltage imbalance on the second coil by the voltage of a small mutual inductance placed in the bore of the first coil. This method allows the second coil detection bridge to be impervious during the discharge of the first coil. The detection system principle is presented in figure 9 .

\section{Experimental settings and first results}

\subsection{Temperature acquisition}

Temperature measurements are made by four wire resistive sensors connected in series and powered by a precision current source. Contrary to the previous experiments where different types of sensors were used, all the sensors are Pt1000s, easy to use but commonly limited to around $30 \mathrm{~K}$ where their $R(T)$ characteristic ceased to be linear. We calibrated various Pt1000s down to $12 \mathrm{~K}$ using a Cernox thermometer as a reference and observed that measurements with this kind of sensor and an appropriate fitting were possible with a sufficient precision ( $\pm 1 \mathrm{~K}$ around $15 \mathrm{~K}$ ) to monitor the device operation.

Measurements with simple and disposable sensors permitted us to easily monitor the temperature in an increased number of locations inside the machine, which was useful to verify its performance. This kind of sensor is of course more sensitive to magnetic flux density than a Cernox one, but even if the values drift a little during experiments, safety of operation is still possible to assert.

Data acquisition is provided by a digital voltmeter with a 48 channel switching unit. Results are transmitted to a computer and collected by means of a Labview ${ }^{\circledR}$ program. The fastest scanning time of the whole set of channels is $1 \mathrm{~s}$. 


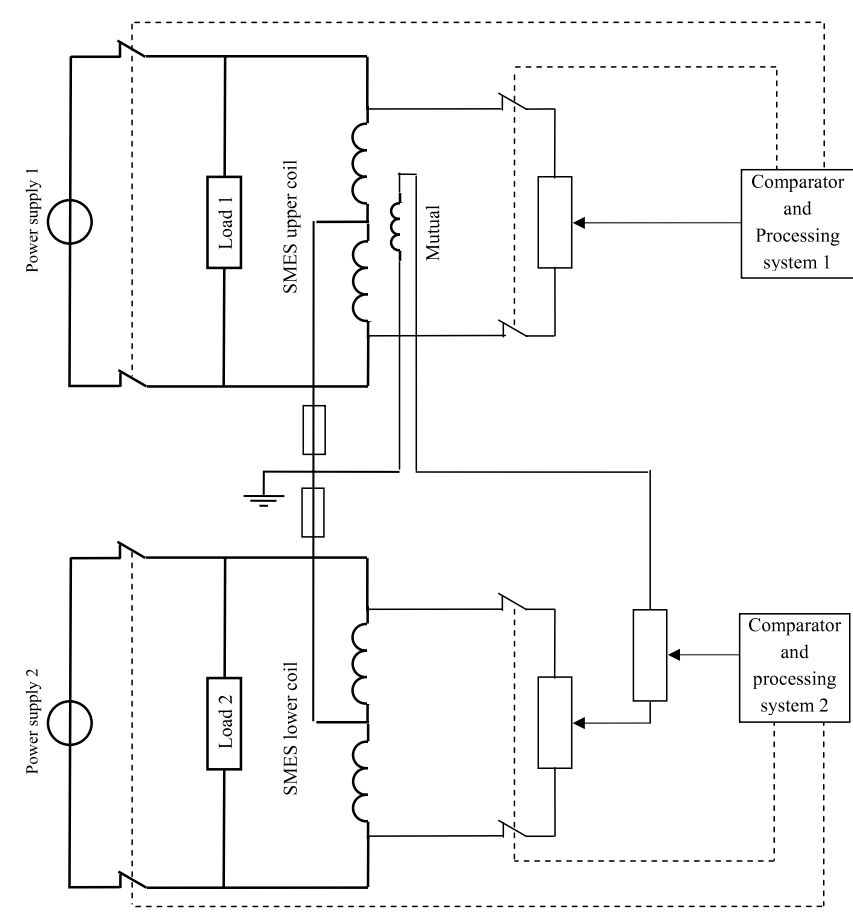

Figure 9. Transition detection system.

\subsection{First cooling results}

5.2.1. Cooling time. The SMES II was first tested in April 2009. Forty temperatures were measured: on each pancake cooling plate, close to the cryocoolers, on the different thermalizations and on the thermal screen, etc. During the cooling, the current source powering the sensors was set to increasing values, from 10 to $500 \mu \mathrm{A}$, to ensure enough precision without heating the sensors too much. Frequent inversions of the current source were performed to check the existence of thermoelectric voltages.

The cooling down takes approximately one week, about the same time as with the first version. Nevertheless, the cooling of the coil itself is much faster: it takes around 2.5 days to have the coil windings below $20 \mathrm{~K}$ (figure 10). The remnant time is necessary to get the thermal screen and current lead thermalizations to their minimal temperatures and to fully stabilize the coils, whose final temperature is at the limit of our sensors' calibration, around $12 \mathrm{~K}$. The losses may thus be estimated as around $2 \mathrm{~W}$, which is consistent with the design. This estimation is not very precise as the relation between temperature and cooling power for each cryocooler is not known with a good accuracy below $20 \mathrm{~K}$.

5.2.2. Liquid nitrogen cooling. As was foreseen, operation without liquid nitrogen is possible only with limited current, the cold head of the current lead cryocooler being over $50 \mathrm{~K}$. The temperature evolution of the two thermalization plates of one of the current leads after filling the nitrogen tank is presented in figure 11 (upper graph). The additional cooling power provided by LN2 lowers the temperature of this cold head down to around $35 \mathrm{~K}$, while the coils' temperatures do

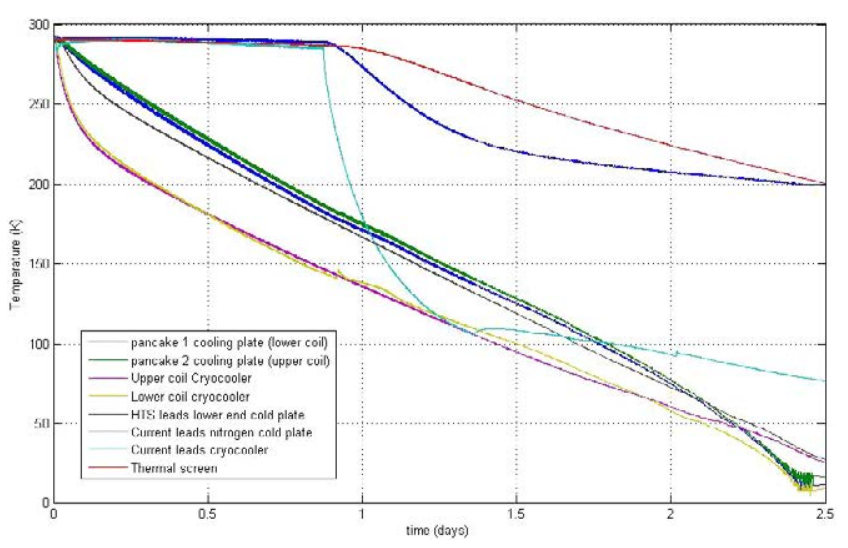

Figure 10. First cooling of the windings.

not change perceptibly. This result is in good agreement with the design objective, $34 \mathrm{~K}$.

The 651 tank designed to provide $30 \mathrm{~h}$ worth of cooling power when the coils are not in use has to be refilled practically every $26 \mathrm{~h}$ (figure 11, lower graph starts immediately after refilling). Considering this nitrogen consumption, the heating power on the tank is evaluated roughly at $100 \mathrm{~W}: 30 \mathrm{~W}$ is due to the thermal losses of the tank, this high value being explained by the lack of superisolation between the tank and the cryostat upper flange. The remnant $70 \mathrm{~W}$ represents the power required to cool the current lead system, close to the expected value of $64 \mathrm{~W}$ (eight current leads creating a loss of $8 \mathrm{~W}$ each under zero current, see table 4).

\subsection{First electrical tests}

The first electrical tests were made to adjust the transition detection system. Each coil was powered with a low frequency $(10 \mathrm{mHz})$ sinusoidal signal up to $20 \mathrm{~A}$, the other coil being in open circuit in order to adjust the two bridges independently. The compensation system of the lower coil (secondary bridge with mutual presented in section 4.2) was adjusted a second time, varying the current on the upper coil with the lower coil short-circuited.

Figure 12 presents the ramping under constant voltage of both coils, up to $40 \mathrm{~A}$, followed by the sequential discharges of the upper coil (with the consequent lower coil overcharge) and then the lower coil. It can be observed that the detection bridge voltage on the upper coil is affected by variations of the current in the lower coil. On the contrary, the detection bridge of the lower coil, which is compensated, is unaffected, although the variation of the current during the upper coil discharge is fast.

The coils' inductances were obtained by ramping the current up under constant voltage $(20 \mathrm{~V})$. The voltage value and the current evolution are used to calculate the input power, which is integrated to get the total energy evolution. A polynomial fitting of the energy evolution against current (figure 13) makes it possible to evaluate the inductance with a good precision through the following equation:

$$
E_{\text {input }}=\frac{1}{2} L I^{2}+R I^{2} t=E_{\text {stored }}+E_{\text {dissipated }} .
$$



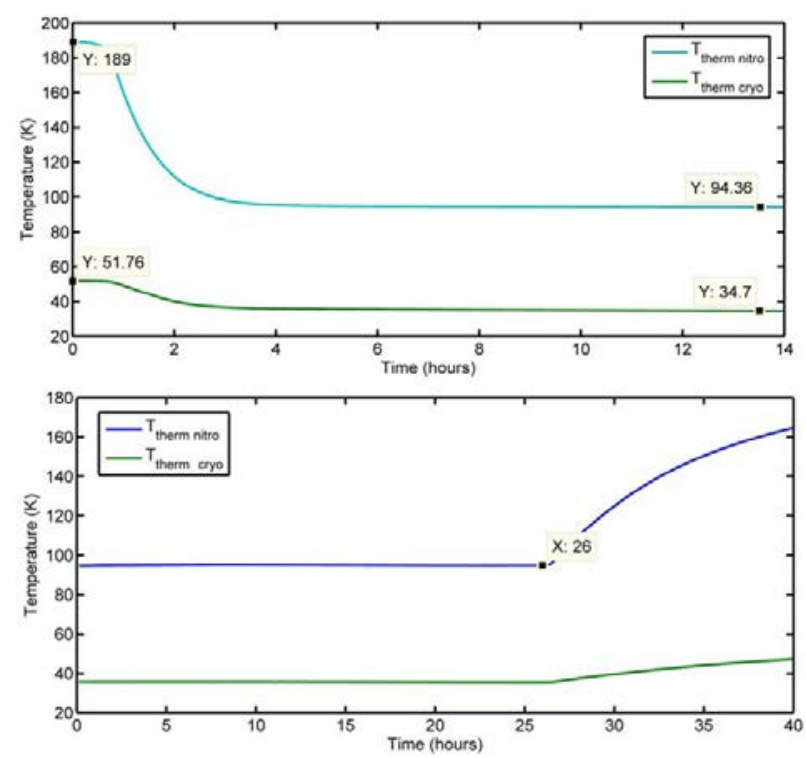

Figure 11. Nitrogen cooling of the current leads' intermediate thermalization: temperature decrease (above) and nitrogen consumption (below).

This method makes it possible to separate the energy stored in the inductance from the energy dissipated in the coils' resistive elements, which is especially important for the lower coil which has six current leads. The results, $4.23 \mathrm{H}$ and $6.56 \mathrm{H}$ respectively for the lower and upper coils, are in good agreement with the expected values calculated using the axisymmetric 2D finite element model of the coils presented above in figure $4(4.3$ and $6.6 \mathrm{H})$.

The coupling between the two coils was evaluated by ramping up the upper coil and discharging it while the lower coil was in open circuit, and measuring the ratio between the upper coil and lower coil voltages. The coupling observed is a little higher than expected, 15.5 instead of $14 \%$. This may be explained by a lower than expected distance between the coils, due to the fact that thermal contraction of the fiber glass spacer was not considered during the design. Another method is to measure the current increase in the short-circuited lower coil during the upper coil discharge, as shown in figure 12. The results obtained are similar, but this method is less accurate due to the influence of the self-discharge speed of the coils in short-circuit.

Finally, each coil was repeatedly ramped up to $200 \mathrm{~A}$ (figure 14). At this level, the conductor starts to dissipate but the dissipation level does not drift, which demonstrates that the cooling system is satisfactory.

\section{Conclusion}

The SMES II demonstrator design presented in this paper makes it possible to obtain fast sequential discharges $(4 \mathrm{kV})$ of identical energies up to $200 \mathrm{~kJ}$, and to test XRAM operation with three stages. With the optimized current lead thermal design presented, multiple high voltage compliant current leads can be conduction-cooled with the cooling power of an AL

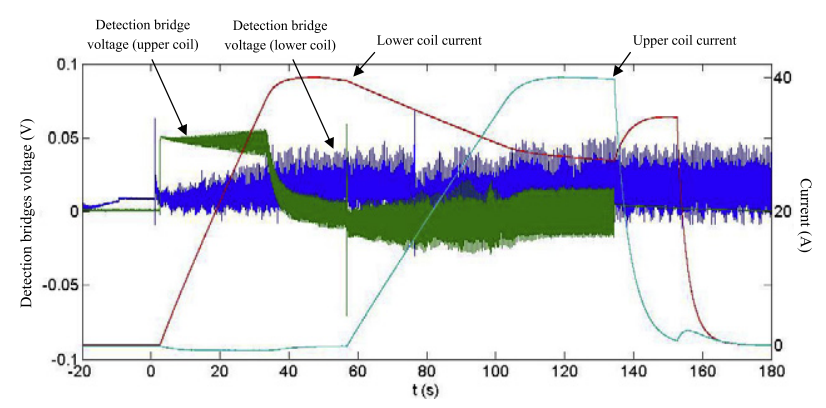

Figure 12. Current evolution and dissipating voltage measurement on the coils during sequential charge and discharge.
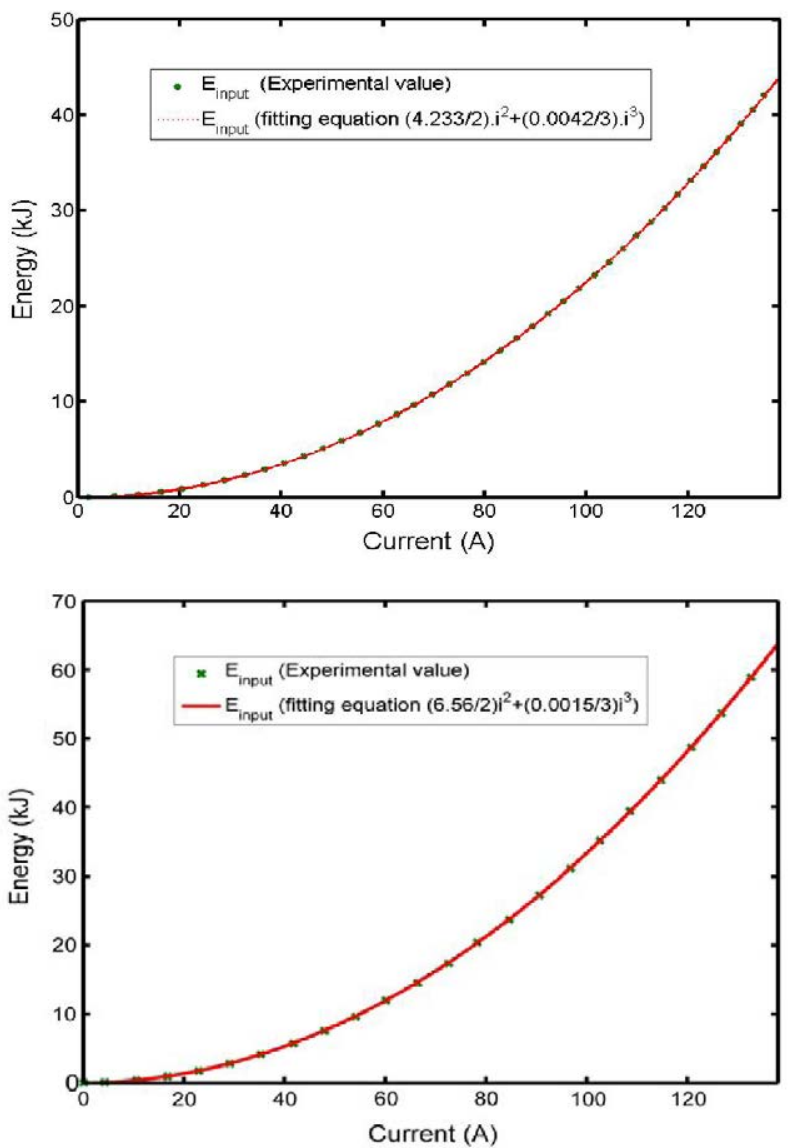

Figure 13. Energy evolution during ramping of the lower coil (above) and the upper coil (below).

330 GM cryocooler. This is obtained by using two-stage thermalizations for the resistive segments of the current leads, the first thermalization being cooled by conduction from a liquid nitrogen tank fitted in the SMES cryostat. This is facilitated by the use of adapted thermalization interfaces, giving good electrical insulation with an increased thermal conduction when compared to previously used interfaces.

The first tests prove that the cooling system behavior matches the simulations, in terms of operation temperature and required cooling power. Operations with limited current, up to around $100 \mathrm{~A}$, made it possible to measure 

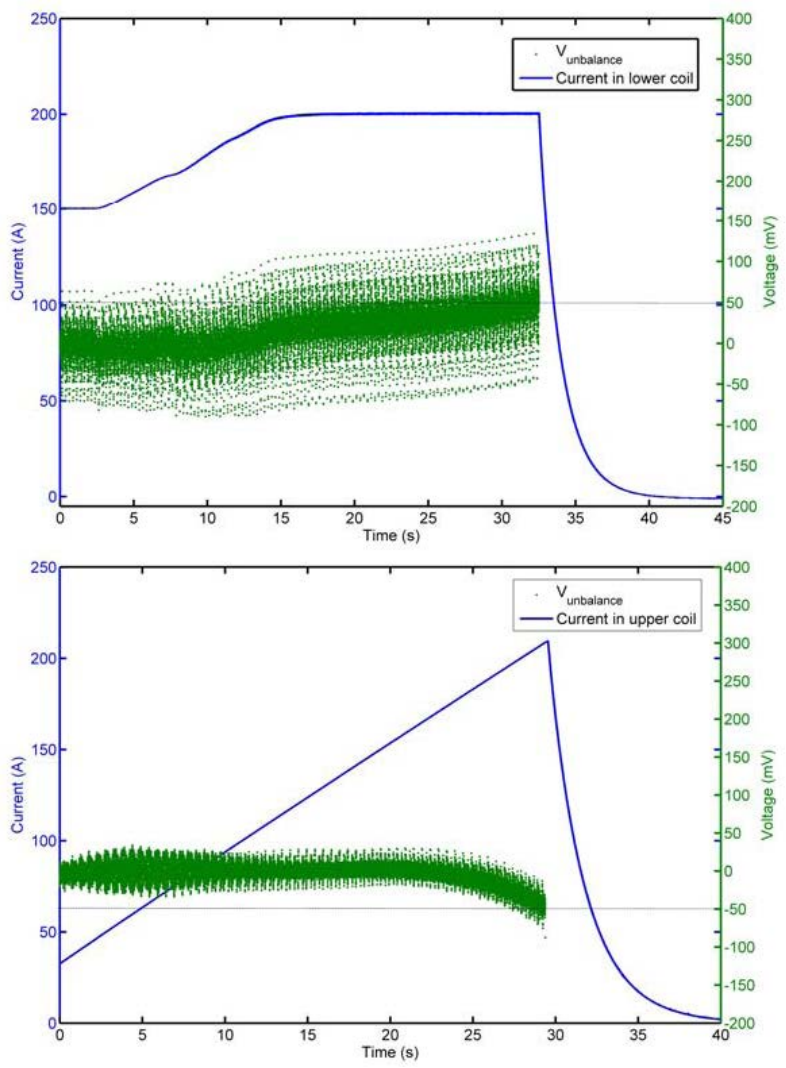

Figure 14. Upper (above) and lower (below) coil current ramping [19].

inductances and coupling values close to the expected ones. Full power operation of the coils has already been tested to prove the demonstrator's capabilities as a pulse power source, especially for direct and indirect powering of an electromagnetic launcher [19]. The good efficiency of the energy discharges obtained demonstrated the interest of SMES for EML powering.

\section{Acknowledgments}

This work is supported by the DGA (French General Delegation for Ordnance), in cooperation with ISL (Saint Louis Institute) within the framework of the contract no. 06 701460075 96. The authors are pleased to thank G André, G Barthélémy, A Boulbès, P Hostachy, L Germani and J Vialle for their essential technical contribution. They also thank O Exchaw and G Simiand for the electronic protection system.

\section{References}

[1] Luongo C A 1996 Superconducting storage systems: an overview IEEE Trans. Magn. 32 2214-23

[2] Moon F C 1982 The virial theorem and scaling laws for superconducting magnet systems $J$. Appl. Phys. 53 9112-21

[3] Lehmann P, Peter H and Wey J 2001 First experimental results with the ISL 10 MJ DES railgun PEGASUS IEEE Trans. Magn. 37 435-9

[4] Lehmann P, Reck B, Vo M D and Behrens J 2007 Acceleration of a suborbital payload using an electromagnetic railgun IEEE Trans. Magn. $\mathbf{4 3}$ 480-5

[5] Bae J H, Kim S H, Kim H J, Sohn M H, Seong K C and Kim H M 2009 Design, fabrication and evaluation of a conduction cooled HTS magnet for SMES Physica C 469 1794-8

[6] Xiao L Y et al 2008 Fabrication and tests of a 1 MJ HTS magnet for SMES IEEE Trans. Appl. Supercond. 18 770-3

[7] Shikimachi K et al 2005 Development of MVA class HTS SMES system for bridging instantaneous voltage dips IEEE Trans. Appl. Supercond. 15 1931-4

[8] Ichinose A, Kasahara H, Sakaki H, Akita S, Ishiyama A and Maruyama A et al 2005 Research and development of high-Tc SMES IEEE Trans. Appl. Supercond. 15 1947-50

[9] Kim W S et al 2006 Design of HTS magnets for a $600 \mathrm{~kJ}$ SMES IEEE Trans. Appl. Supercond. 16 620-3

[10] Tixador P et al 2008 First tests of a 800 kJ HTS SMIES IEEE Trans. Appl. Supercond. 18 774-8

[11] Lehmann P 2003 Overview of the electric launch activities at the French-German Research Institute of Saint-Louis (ISL) IEEE Trans. Magn. 39 24-8

[12] Weck W, Ehrhart P, Muller A, Scholderle H and Sturm E 1999 Demonstration of a superconducting inductive pulsed power supply at simulated load conditions IEEE Trans. Magn. 35 383-7

[13] Cryomech available from: http://www.cryomech.com.

[14] Tixador P et al 2007 Design and first tests of a $800 \mathrm{~kJ}$ HTS SMES IEEE Trans. Appl. Supercond. 17 1967-72

[15] Choi J H et al 2008 The electrical insulation design of $600 \mathrm{~kJ}$ conduction cooled HTS SMES IEEE Trans. Appl. Supercond. 18 1394-7

[16] Mariani M et al 2002 Cryocooler cooled HTS current leads for a $1 \mathrm{MJ} / 1 \mathrm{MW}$-class SMES system IEEE Trans. Appl. Supercond. 12 1293-6

[17] Badel A and Tixador P 2010 Détecteur de transition de bobine supraconductrice French Patent Specification 10/00663

[18] Badel A, Tixador P, Simiand G and Exchaw O 2010 Quench detection system for twin coils HTS SMES Cryogenics 50 674-81

[19] Badel A, Tixador P and Dedié P 2011 Test of a twin coil HTS SMES for high power pulse operation IEEE Trans. Appl. Supercond. doi:10.1109/TASC.2010.2090321 